\title{
TANTANGAN MERINTIS KEMITRAAN EKOWISATA MANGROVE: LESSON LEARNING BERSAMA MASYARAKAT PESISIR BELAWAN
}

\author{
Pindi Patana ${ }^{1}$, Achmad Delianur Nasution², Zulham Afandi Harahap ${ }^{3}$, Prihatin \\ Lumbanraja $^{4}$, Arlina Nurbaity Lubis ${ }^{4}$, Onrizal ${ }^{1}$, Rudi Hartono ${ }^{1}$, Indra Aulia ${ }^{5}$ \\ ${ }^{1}$ Program Studi Kehutanan, Fakultas Kehutanan Universitas Sumatera Utara \\ ${ }^{2}$ Departemen Arsitektur, Fakultas Teknik Universitas Sumatera Utara \\ ${ }^{3}$ Program Studi Manajemen Sumberdaya Perairan Universitas Sumatera Utara \\ ${ }^{4}$ Program Studi Manajemen, Fakultas Ekonomi dan Bisnis Universitas Sumatera Utara \\ ${ }^{5}$ Program Studi Teknologi Informasi, Fakultas Ilmu Komputer dan Teknologi Informasi \\ Email: pindi@usu.ac.id, aan.nasution@gmail.com,zulham.apandy@usu.ac.id, prihatin@usu.ac.id, \\ arlinalubis@yahoo.com, onrizal@usu.ac.id, rudihartono@usu.ac.id,indraaulia@usu.ac.id
}

\begin{abstract}
Abstrak
Masyarakat Kampung Nelayan Seberang Belawan sudah ada sejak 1957. Sejumlah nelayan awalnya menjadikan pinggiran hutan mangrove di Pesisir Belawan sebagai tempat singgah sementara selama melaut, namun seiring waktu kini berkembang menjadi perkampungan nelayan. Kehidupan nelayan pesisir masih sangat tradisonal dan cenderung marginal dari kegiatan pembangunan. Mereka mengandalkan penghidupan dari hasil tangkapan laut seperti ikan, kepiting dan udang. Keberadaan hutan mangrove yang berstatus hutan lindung dan hutan produksi terbatas di sekitar perkampungan nelayan belum banyak berdampak terhadap kesejahteraan. Bahkan di tahun 2000an banyak yang memanfaatkan mangrove secara illegal untuk dibuat menjadi arang, sehingga menurunkan produktivitas tangkapan laut serta mengancam kelestarian lingkungan. Kegiatan pengabdian kepada masyarakat dengan konsep Desa Binaan USU di Pesisir Belawan ini dirancang dengan tujuan untuk meningkatkan kesejahteraan nelayan melalui pemanfaatan jasa lingkungan ekowisata hutan mangrove berbasis ekonomi masyarakat. Metoda yang digunakan LPPM USU yaitu memfasilitasi pembentukan kelembagaan wisata dengan pola kemitraan nelayan dan Dinas Kehutanan Provinsi Sumatera Utara serta pelatihan pengelolaan ekowisata. Analisis potensi wisata menunjukkan hutan mangrove sangat terbuka untuk dikembangkan menjadi ekowisata di Pesisir Belawan. Pengelolaan ekowisata diharapkan menjadi pintu akses masyarakat terhadap pemanfaatan hutan mangrove secara legal serta adanya alternatif penghidupan yang berkelanjutan.
\end{abstract}

Kata Kunci: Lesson learning, Belawan, mangrove, ekowisata

\section{PENDAHULUAN}

Kawasan pesisir seringkali mendapat kesan yang identik dengan identik suasana kumuh dan kotor. Padahal sejatinya dahulu sejarah pesisir nusantara pernah menorehkan kejayaan sebagai pusat peradaban dan perdagangan. Selayaknya kawasan pesisir menjadi jantung ekonomi yang sangat penting karena sekitar 80 persen kegiatan ekonomi Indonesia terkait dengan wilayah ini, seperti perikanan dan pelabuhan, pergudangan, industri, kepariwisatawaan, dan pertanian. Umumnya sebagian besar penduduk di wilayah pesisir memiliki mata pencaharian dengan cara memanfaatkan sumberdaya alam baik sebagai petani sawah, nelayan maupun petani tambak.

Kampung Nelayan, Medan Belawan merupakan masyarakat pesisir yang kehidupannya sangat tergantung pada sumberdaya pesisir, yakni mangrove dan perairannya. Mangrove menyediakan

Lingkungan Hidup dan Kebencanaan 
dukungan kehidupan tidak saja bagi masyarakat pesisir namun juga bagi kehidupan biota perairan pesisir Onrizal et al. (2016). Ketergantungan pada sumberdaya pesisir yang tinggi menyebabkan eksploitasi berlebihan sehingga menimbulkan degradasi degradasi hutan mangrove dan penurunan kualitas perairan pesisir. Pengelolaan sumberdaya pesisir yang tidak lestari dapat mengancam kelestarian hasil tangkap nelayan sehingga mengancam penghidupannya (Onrizal et al. 2009).

Hutan mangrove merupakan ekosistem yang unik sehingga sangat atraktif bagi kegiatan wisata alam (ekowisata) (Wardhani, 2011, Onrizal et al., 2016, Situmorang, 2018). Keberadaan kampung nelayan di pesisir belawan secara geografis sangat strategis karena dekat dengan pelabuhan terbesar ke3 di Indonesia dan ibukota Provinsi Sumatera Utara. Kampung Nelayan Pesisir Belawan sangat potensial menjadi pusat ekowisata mangrove Sumatera Utara. Saat ini destinasi ekowisata mangrove di Sumatera Utara masih didominasi oleh Desa Sei Nagalawan di Kabupaten Serdang Bedagai dan kemudian disusul dalam beberapa tahun belakangan oleh Desa Lubuk Kertang di Kabupaten Langkat.

Ada beberapa keunggulan Kampung Pesisir Belawan, baik dari sisi manusia maupun sumberdaya alamnya. Kampung Nelayan Pesisir Belawan menjadi salah satu lumbung atlet dayung nasional. Berbagai prestasi baik lokal, nasional dan internasional ditorehkan oleh warga kampung nelayan ini. Dari sisi alamnya, berbagai jenis biota air dan burung-burung air ayng hidup di ekosistem mangrove menjadi daya tarik bagi pengunjung. Kondisi ini dapat menjadi modal yang sangat baik untuk pengembangan ekowisata mangrove dan bahari di wilayah tersebut.

Namun demikian keberadaan Kampung Nelayan pesisir belawan belum mendapat perhatian serius dari pemerintah. Kesejahteraan penduduknya masih memperihatinkan demikian juga pembangunan sarana dasar masih sangat minim. Keberadaan hutan mangrove yang merupakan kawasan hutan lindung dan hutan produksi tterbatas juga terancam oleh berbagai aktifitas illegal seperti penebangan liar, tambak liar dan pemeukiman.

Pengembangan ekowisata yang diusung dalam skema Desa Binan Universitas Sumatera Utara (USU) ini bertujuan untuk mengembangkan potensi Pesisir Belawan sebagai destinasi wisata dengan tetap menjaga kelestarian ekosistem mangrove dan meningkatkan kesejahteraan warganya. Kemitraan yang dibangun menggabungkan unsur Dinas Kehutanan Sumatera Utara, Kelompok nelayan dan USU. Manfaat dari kegiatan ini diharapkan dapat menyiapkan fondasi bagi masyarakat Kampung Nelayan Seberang sebagai calon pengelola ekowisata yang berkelanjutan baik dari sisi keterampilan (softskill) maupun perangkat dasar fasilitas ekowisata.

\section{METODE}

Kegiatan pengabdian Desa Binaan USU tahun pertama ini dilakukan di Desa Kampung Nelayan Sebrang, Pesisir Belawan selama lima bulan dalam tahun anggaran 2020 dan direncanakan menjadi kegiatan multi years. Langkah yang dilakukan dalam membangun kawasan ekowisata Pesisr Belawan tahun ke-1 ini meliputi:

1) Survey potensi kawasan Pesisir Belawan

2) Focus group discussion (FGD) calon mitra

3) Wawancara ahli

4) Pelatihan ekowisata

5) Koordinasi lintas sektor

6) Pembangunan tahap awal jalur trekking mangrove

Survey potensi meliputi semua kondisi alam yang bisa dijadikan daya tarik wisata menurut panduan objek dan daya tarik wisat alam (ODTWA) kementrian Kehutanan. Wawancara dilakukan terhadap ahli yang mewakili bidang ekonomi, sosial budaya, teknik dan lingkungan. Data lapangan yang terkumpul selanjutnya dianalisis secara deskriptif kualitatif serta menggunakan matrik SWOT. Selanjutnya analisis SWOT digunakan untuk mengevaluasi kekuatan (strengths), kelemahan (weaknesses), peluang (opportunities), dan ancaman (threats) dalam suatu proyek (Rauch, 2007).

Dua faktor termasuk kriteria IFAS (Internal Factors Analysis Summary) yaitu kekuatan dan kelemahan sedangkan dua lagi termasuk kriteria EFAS (External Factors Analysis Summary) yaitu peluang dan ancaman. Kadang-kadang teknik SWOT diterapkan dengan menggabungkan dengan aplikasi lain di berbagai bidang seperti lingkungan (Kurttila et al., 2000; Leskinen et al., 2006; Masozera et al., 2006), pariwisata (Kajanus et al., 2004), pariwisata

Lingkungan Hidup dan Kebencanaan

512 
(Kajanus et al., 2006), dan pertanian (Shrestha et al., 2004).

\section{HASIL DAN PEMBAHASAN}

\section{Potensi dan Permasalahan Kampung Nelayan Sebrang}

Kampung Nelayan Sebrang Belawan awalnya merupakan tempat persinggahan sementara nelayan dari Karang Gading, Langkat sejak tahun 1957. Umumnya mereka berasal dari suku melayu. Seiring dengan waktu jumlah mereka terus bertambah dan akhirnya sebagian menetap di pinggiran hutan mangrove. Kondisi kehidupan nelayan yang mengdalkan pada hasil laut hanya membuat mereka bisa bertahan hidup saja. Kondisi yang sangat minim ditambah perhatian terhadap nfrastruktur di perkampungan yang sangat minim menyebabkan kondisi perkampungan teras kumuh sehingga berpengaruh terhadap kesehatan lingkungannya.

Keberadaan mangrove bagi Nelayan Sebrang merupakan sumber penghidupan. Mereka sangat menggantungkan pendapatan dari hasil kepiting bakau, atau tangkapan laut lainnya. Oleh karena itu masyarkat sangat menentang terhadap setiap upaya pengrusakan mangrove untuk dijadikan arang terutama yang dilakukan secar liar.

Alternatif penghidupan yang sangat minim inilah yang mendorong LPPM USU untuk membantu masyarakat melalui pengembangan ekowisata dalam skema Desa Binaan USU. Untuk mengukur potensi dan permaslahan pengembangan ekowisata ini dilakukan analisis SWOT dengan faktor-faktor internal dan ekternal seperti dalan Tabel 1.

Tabel 1. Faktor internal dan ekternal pengembangan ekowisata Pesisir Belawan

\begin{tabular}{ll}
\hline \multicolumn{1}{c}{$\begin{array}{c}\text { Kekuatan } \\
\text { (Strengths) }\end{array}$} & \multicolumn{1}{c}{$\begin{array}{c}\text { Kelemahan } \\
\text { (Weekness) }\end{array}$} \\
\hline S1. Aksebilitas & W1. Kelembagaan wisata \\
S2. Geografis dan SDA & W2. SDM \\
S3. Akomodasi & W3. Penataan kawasan \\
$\begin{array}{l}\text { S4. Kearifan lokal } \\
\text { S5. Kooperatif }\end{array}$ & W4. Perhatian pemerintah \\
\hline \multicolumn{1}{c}{ Peluang } & \multicolumn{1}{c}{$\begin{array}{c}\text { Ancaman } \\
\text { (Thportunity) }\end{array}$} \\
\hline O1. Paket wisata bahari $)$
\end{tabular}
O2. Dana CSR
T2. Sengketa lahan
O3. Wisata edukasi
T3. Pandemi COVID 19
O4. Event dayung

Pengujian terhadap semua faktor internal dan ekternal dilakukan dengan melakukan wawancara terhadap para pihak yang mewakili bidang ekologi, ekonomi dan sosial. Hasil perhitungan SWOT disajikan seperti pada Tabel 2. Secara internal Kampung Nelayan Seberang memiliki kekuatan untuk dikembangkan sebagai calon destinasi wisata khususnya di kota medan dan sekitarnya dengan nilai IFAS positif $(0,23)$. Sedangkan secara ekternal peluang yang ada dapat menekan ancaman di sekitar kawasan sehingga dihasilkan nilai EFAS positif $(0,65)$. Secara keseluruhan analisis SWOT terhadap kondisi di Kampung nelayan menempatkannya pada kuadran I seperti tersaji pada Gambar 1.

\section{Tabel 2. Perhitungan IFAS dan EFAS}

\begin{tabular}{|c|c|c|c|c|c|c|c|c|c|c|c|}
\hline \multirow[b]{2}{*}{ Faktor } & \multicolumn{8}{|c|}{ Responden } & \multirow[b]{2}{*}{ B obot } & \multirow[b]{2}{*}{ Rate } & \multirow[b]{2}{*}{ Skor } \\
\hline & 1 & 2 & 3 & 4 & 5 & 6 & 7 & Jumlah & & & \\
\hline S1 & 4 & 2 & 2 & 3 & 3 & 4 & 2 & 18 & 0,10 & 2,57 & 0,26 \\
\hline $\mathrm{S} 2$ & 4 & 4 & 3 & 2 & 3 & 3 & 3 & 19 & 0,11 & 2,71 & 0,29 \\
\hline $\mathrm{S} 3$ & 4 & 3 & 3 & 4 & 3 & 4 & 3 & 21 & 0,12 & 3,00 & 0,35 \\
\hline $\mathrm{S} 4$ & 4 & 3 & 4 & 4 & 3 & 4 & 3 & 22 & 0,12 & 3,14 & 0,39 \\
\hline S5 & 4 & 3 & 3 & 3 & 2 & 3 & 4 & 18 & 0,10 & 2,57 & 0,26 \\
\hline Jumlah & & & & & & & & & & & 1,54 \\
\hline W1 & 4 & 3 & 4 & 2 & 4 & 3 & 4 & 20 & 0,11 & 2,86 & 0,32 \\
\hline w2 & 3 & 3 & 4 & 2 & 3 & 3 & 4 & 18 & 0,10 & 2,57 & 0,26 \\
\hline w3 & 4 & 4 & 4 & 2 & 4 & 3 & 4 & 21 & 0,12 & 3,00 & 0,35 \\
\hline W4 & 4 & 3 & 4 & 4 & 3 & 4 & 4 & 22 & 0,12 & 3,14 & 0,39 \\
\hline Total & & & & & & & & 179 & 1,00 & & 1,32 \\
\hline IFAS & & & & & & & & & & & 0,23 \\
\hline $\mathrm{O} 1$ & 4 & 3 & 3 & 4 & 3 & 4 & 4 & 21 & 0,14 & 3,00 & 0,43 \\
\hline $\mathrm{O} 2$ & 4 & 3 & 4 & 3 & 3 & 4 & 3 & 21 & 0,14 & 3,00 & 0,43 \\
\hline $\mathrm{O} 3$ & 4 & 4 & 4 & 4 & 4 & 4 & 4 & 24 & 0,16 & 3,43 & 0,56 \\
\hline $\mathrm{O} 4$ & 4 & 3 & 4 & 3 & 3 & 4 & 4 & 21 & 0,14 & 3,00 & 0,43 \\
\hline Jumlah & & & & & & & & & & & 1,85 \\
\hline $\mathrm{T} 1$ & 4 & 4 & 4 & 4 & 4 & 4 & 4 & 24 & 0,16 & 3,43 & 0,56 \\
\hline $\mathrm{T} 2$ & 4 & 3 & 4 & 2 & 2 & 4 & 3 & 19 & 0,13 & 2,71 & 0,35 \\
\hline T3 & 2 & 4 & 4 & 2 & 2 & 3 & 4 & 17 & 0,12 & 2,43 & 0,28 \\
\hline Total & & & & & & & & 147 & 1,00 & & 1,19 \\
\hline EFAS & & & & & & & & & & & 0,65 \\
\hline
\end{tabular}

Lingkungan Hidup dan Kebencanaan 


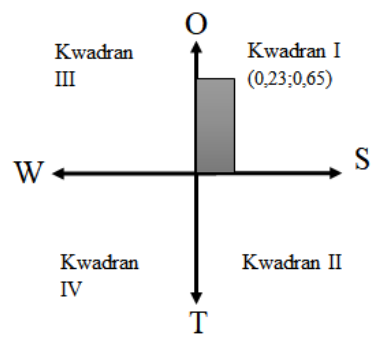

Gambar 1. Kwadran ekowisata Pesisir Belawan Hasil analisis SWOT menunjukkan kawasan Pesisir Belawan sangat potensial untuk dikembangkan sebagai objek ekowisata. Strategi yang biasa digunakan strategi pengembangan atau agresif. Strategi ini menekankan pada optimalisasi kekuatan untuk memanfaatkan peluang yang ada (Rauch 2007).

Potensi mangrove dan keberadaan pulau burung sangat menarik sebagai objek wisata. Selain itu akses yang relatif mudah juga dapat menjadi kekuatan objek wisata ini. Wisata air yang cukup potensial untuk dikembangkan adalah dayung. Kampung Nelayan merupakan salah satu lumbung atlet dayung baik lokal maupun nasional. Harapannya di lokasi ini dapat diadakan event nasional yang bisa meningkatkan jumlah kunjungan wisatawan. Sajian makanan khas seafood juga merupakan potensi yang bisa dikembangkan mengingat masyarakat disana banyak yang mengandalkan pendapatannya dari kepiting bakau. (Gambar 2).

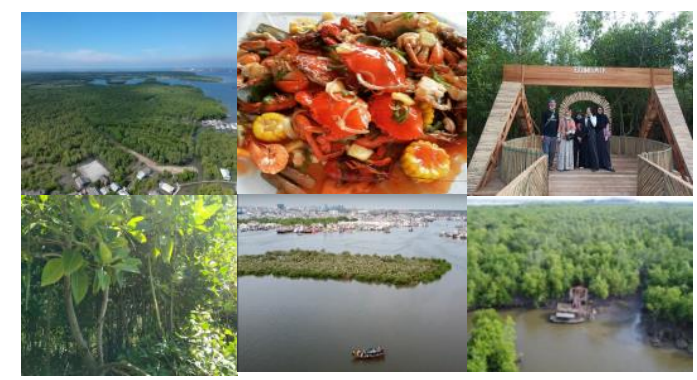

Gambar 2. Potensi Ekowisata Pesisir Belawan

Pesisir Belawan berjarak hanya $23 \mathrm{~km}$ dari ibukota Medan dan bisa ditempuh selama 39 menit dengan menggunakan jalan tol. Selanjutnya dari pelabuhan naik perahu selama \pm 10 menit untuk sampai di hutan mangrove. Lokasi ini jelas lebih dekat dari lokasi wisata mangrove lainnya seperti
Serdang Bedagai (58 km). Meskipun demikian perlu ada penataan lokasi di sekitar pelabuhan penyebrangan terutama lahan parkir untuk lebih memberikan kenyamanan para wisatawan.

Lokasi wisata yang dekat dengan pelabuhan memberi akses yang mudah pada penyedian sarana akomodasi. Di sekitar Belawan sendiri terdapat sarana penginapan yang dapat menjadi alternatif bagi para wisatawan yang ingin merasakan suasana alam di Pesisir Belawan. Peta lokasi pengabdian ditunjukkan dalam Gambar 3.

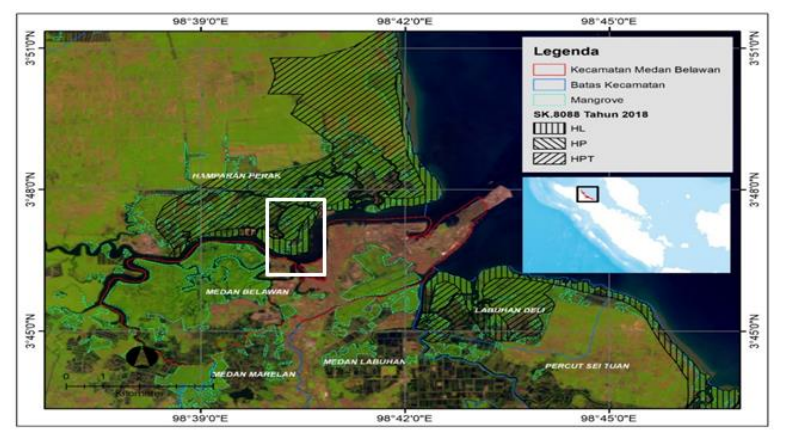

Gambar 3. Peta PKM Desa Binaan Pesisir Belawan

Sikap kooperatif masyarakat dalam setiap kegiatan pengabdian di Kampung Nelayan juga merupakan nilai lebih dari sisi sosial. Komunikasi dan kepercayaan yang baik antara LPPM USU dan masyarakat Kampung Nelayan Seberang sangat membantu akselerasi pelaksanaan setiap program PKM di wilayah ini.

Kelemahan yang menjadi pekerjaan rumah dalam kegiatan PKM ini terkait dengan kelembagaan dan perhatian pemerintah. Masyarakat masih belum memiliki lembaga berbadan hukum untuk mengelola ekowisata. Oleh karena itu melalui kegiatan PKM ini masyarakat difasilitasi untuk membentuk Koperasi. LPPM USU menggandeng Dinas Koperasi SUMUT untuk membantu dalam setiap tahap pembentukannya. Perhatian pemerintah terhadap Kp. Nelayan Seberang juga masih minim. Permasalahan ini dipicu salah satunya oleh administrasi kependudukan yang kacau. 90\% warga Kp. Nelayan Seberang memiliki Kartu Tanda Penduduk (KTP) Kota Medan, padahal secara administratif lokasi ini masuk Desa Paluh Kurau, Kec. Hamparan Perak, Kabupaten Deli Serdang.

Lingkungan Hidup dan Kebencanaan 
Kerancuan administrasi penduduk ini menyebabkan proses pembangunan tidak berjalan lancar.

Sengketa lahan bisa menjadi ancaman bila tidak ada ketegasan pemerintah. Banyak hutan mangrove yang dirambah dan dijadikan lahan tambak secara illegal. Permasalahan ini sudah lama terjadi. Oleh karena itu dengan adanya kegiatan ekowisata berbasis masyarakat ini diharapkan pelestarian kawasan mangrove di Pesisir Belawan bisa menjadi lebih baik.

\section{Pihak Terlibat dan Tahapan Perintisan Ekowisata Pesisir Belawan}

Ekowisata hanya akan berkembang bila ada kerjasama para pihak. Untuk mewujudkan hal itu LPPM USU menginisiasi terbentuknya jejaring dari mulai masyarakat, kelurahan / desa, kecamatan, Dinas Kehutanan Provinsi dan Dinas Koperasi Provinsi Sumatra Utara. Dengan adanya koordinasi para pihak terkait tersebut diharapkan terbangun pola komunikasi yang baik dalam rangka pengembangan ekowisata. Tahapan kegiatan yang sudah dan akan yang dilakukan dalam perintisan ekowisata di Pesisir Belawan meliputi:

a) survey pendahuluan untuk melihat kondisi

b) diskusi dengan masyarakat calon pengelola

c) survey potensi ekowisata dan analisis SWOT

d) diskusi peluang kolaborasi tiga piahak: USU, Dinas Kehutanan Sumut (DISHUTSU) dan masyarakat nelayan

e) pembahasan draft nota kesepahaman MoA (Memorandum of Agreement) antara LPPM USU dengan DISHUTSU

f) penandatangan MoA LPPM USU dan DISHUTSU

g) penentuan lokasi tapak ekowisata mangrove dengan memastikan status yang clear and clean dari dinas kehutanan berdasarkan overlay peta kawasan dan penggunaan hutan

h) perencanaan kelembagaan pengelola ekowisata

i) pelatihan dasar-dasar ekowisata dan pengelolaan wisata yang berkelanjutan

j) perencanaan pembangunan jalur trekking dan selfie spot (masterplan)

k) pelaksanaan pembangunan fasilitas trekking

1) pembentukan Koperasi Nelayan Cinta Mangrove

m) pengembangan jejaring CSR

n) pembuatan program interpretasi o) penyusunan paket Desa Wisata Pesisir Belawan

Berdasarkan rencana pengembangan ekowisata di Pesisir Belawan dibutuhkan waktu minimal 5 tahun untuk meletakkan fondasi yang kokoh pengelolaan ekowisata Pesisir Belawan yang berkelanjutan. Tahun pertama merupakan fase awal dengan fokus pada potensi alam, kondisi sosial masyarakat, penyiapan masterplan, serta pembangunan trekking tahap awal. Tahun kedua penguatan kelembagaan dan pengelolaan ekowisata

dan pembangunan fasilitas trekking tahap ke-2. Tahun ketiga penyiapan program interpretasi dan akomodasi, fasilitas penunjang lainnya serta trekking tahap ke-3. Tahun keempat penyusunan paket wisata dan kerjasama pemasaran. Tahun kelima launching desa wisata unggulan Sumatera Utara. Rangkaian tahapan kegiatan tersebut disajikan dalam road map Pengabdian Desa Binaan seperti pada Gambar 4.

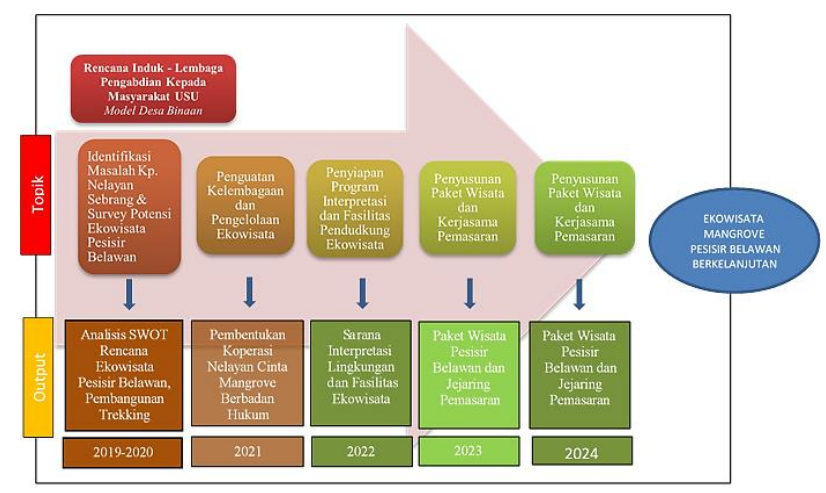

Gambar 4. Peta Jalan Ekowisata Pesisir Belawan

Dalam mewujudkan peta jalan ekowisata Pesisir Belawan tersebut hal-hal penting yang harus dilakukan disajikan dalam diagram tulang ikan (fish bone) seperti pada Gambar 5. Kegiatan PKM Desa Mandisi di Kampung Nelayan ini pada prinsipnya merupakan lanjutan dari kegiatan PKM mono tahun yang sudah dilaksanakan sebelumnya dari mulai 2016. Selama ini potensi mangrove masih belum dimanfaatkan untuk ekowisata, padahal mereka tinggal selama berpuluh-puluh tahun disana. Oleh karena itu kegiatan ini menjadi jembatan untuk mengoptimalkan pemanfaatan hutan mangrove secara lestari.

Lingkungan Hidup dan Kebencanaan 


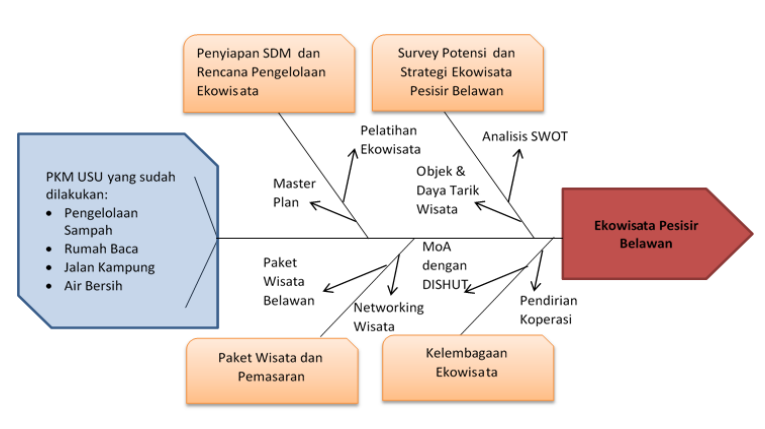

Gambar 5. Fish Bone Langkah Menuju Ekowisata

\section{Kelembagaan Pengelola Ekowisata}

Pengelolaan ekowisata membutuhkan kelembagaan yang baik agar bisa berjalan sukses (Stronza dan Gordillo, 2008). Untuk mewujudkan hal tersebut, program pengabdian ini menyiapkan tiga kegiatan. Pertama, penyiapan sumberdaya pengelola melalui pelatihan ekowisata. Kedua, penyiapan kelengkapan administratif dengan melakukan kesepakatan dengan pihak Dinas Kehutanan Provinsi Sumatera Utara. Ketiga, pembentukan badan hukum koperasi dengan menggandeng Dinas Koperasi Sumatera Utara.

Penyiapan SDM pengelola ekowisata menjadi sangat urgen mengingat masyarakat nelayan belum memiliki pengalaman sama sekali. Oleh karena itu titik tekan materi pada tahap awal ini meliputi dasar-dasar ekowisata serta tentang daya dukung lingkungan. Materi tersebut dipilih agar para calon pengelola bisa memahami perbedaan ekowisata dengan mass tourism. Selain itu mereka juga diajarkan tentang kaidah-kaidah konservasi dalam pengembangan ekowisata.

Lokasi kegiatan ekowisata Pesisir Belawan ini berada di kawasan lindung dan kawasan hutan produksi terbatas. Oleh karena itu untuk memastikan areal yang akan dikelola itu clear and clean, pihak LPPM USU berkoordinasi dengan pihak DISHUTSU. Hal ini untuk mencegah munculnya masalah dikemudian hari akibat overlaying penggunaan kawasan oleh pihak lain. Komunikasi yang dibangun antara LPPM USU dengan DISHUTSU berjalan sangat baik dan penuh keterbukaan sehingga kesepakatan kerjasama pun (MoA) dapat dirampungkan dalam waktu 1 bulan. Kedua belah pihak memahami urgensi kegiatan pengabdian ini dari sisi lingkungan dan ekonomi masyarakat pesisir.

Tahapan berikutnya adalah menyiapkan wadah pengelola ekowisata. Mengingat USU sebagai fasilitator, maka pelaku utamanya adalah masyarakat nelayan itu sendiri. Pada saat dilakukan kegiatan ini, mereka belum memiliki lembaga berbadan hukum sebagai persyratan untuk bermitra dengan DISHUTSU. Berdasrkan hasil kajian dan pertimbang dari DISHUTSU akhirnya ditetapkan kelembagaan yang nantinya akan menjadi wadah resmi pengelola ekowisata yaitu Koperasi. Hal ini mengacu pada peraturan Menteri Lingkungan Hidup dan Kehutanan Republik Indonesia No. P.49/MENLHK/SETJEN/KUM.1/9/2017 tentang Kerjasama Pemanfaatan Hutan Pada Kesatuan Pengelolaan Hutan. Sesuai dengan bunyi Pasal 5 Bab IV tentang pelaku kerjasama dinyatakan bahwa kerjasama pemanfaatan hutan pada KPH dilakukan dengan: perorangan, kelompok masyarakat setempat, BUM Desa, Koperasi setempat, UMKM, BUMD, BUMN atau BUMSI.

Pemilihan koperasi berdasarkan analisis dan pengalaman dari tempat lain, sehingga wadah ini bisa berkesinambungan. Koperasi yang dibentuk ini akhirnya disepakati dengan nama "Koperasi Nelayan Cinta Mangrove". Nama tersebut merupakan penggabungan dari tiga kelompok nelayan yang sudah lama melakukan kegiatan pelestarian mangrove, yaitu: Kelompok Aulia Mangrove, Kelompok Nelayan Bubu Cinta Lingkungan (NBCL) dan Persatuan Kesenian Anak dan Pemuda Nelayan (PEKAN).

Kesepakatan ini merupakan bukti bahwa masyarakat memiliki keinginan kuat untuk saling bekerjasama dalam mengembangkan ekowisata. Tugas tim pengabdian sangat terbantu dengan sikap kooperatif masyarakat. Hal tersebut tidak terlepas dari banyaknya kegiatan pengabdian yang sudah dilakukan LPPM USU sejak 2016. Dalam pembentukan koperasi ini LPPM USU bekerja sama dengan Dinas Koperasi Sumatera Utara. Hal ini disebabkan calon anggota koperasi ini berasal dari tiga wilayah yaitu Medan, Kabupaten Deli Serdang dan Kabupaten Langkat. Proses pembentukan kelembagaan ekowisata Pesisir Belawan disajikan pada Gambar 6.

Lingkungan Hidup dan Kebencanaan 516 


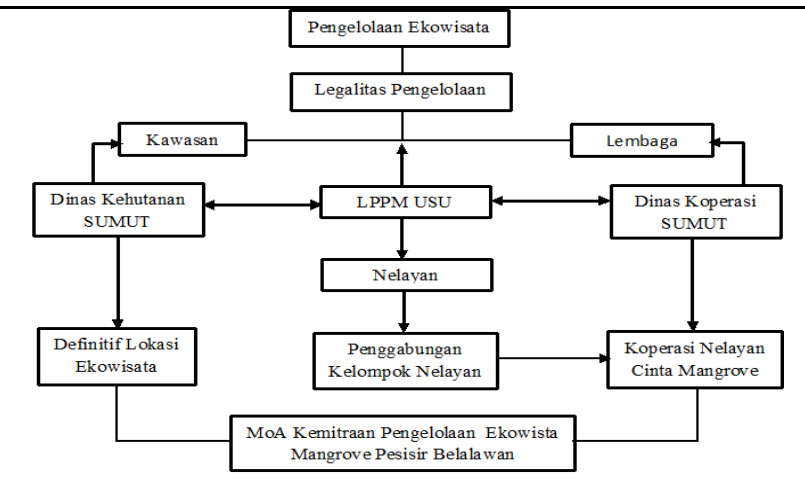

Gambar 6. Alur Pembentukan Kelembagaan Pengelolaan Ekowisata Pesisir Belawan

\section{Mengapa Ekowisata?}

Permasalahan Kampung nelayan merupakan akumulasi kompleksitas ekonomi, sosial budaya dan lingkungan. Oleh karena itu model Desa Binaan USU di Kampung Nelayan ini diharapkan dapat menjawab kompleksitas masalah tersebut di atas. Oleh karena itu ekowisata diharapkan dapat menjadi alternatif solusi pembangunan Pesisir Belawan. Secara definitif ekowisata suatu bentuk perjalanan wisata ke area alami yang dilakukan dengan tujuan mengkonservasi lingkungan dan melestarikan kehidupan dan kesejahteraan penduduk setempat (The Ecotourism Society, 1990 dalam Fandeli, 2000).

Kondisi hutan mangrove serta biota yang ada di Pesisir Belawan sudah lama menjadi sumber penghidupan masyarakat setempat. Kerusakan lingkungan yang telah terrjadi dalam beberapa tahun terakhir sudah banyak dirasakan dampat negatifnya oleh para nelayan dan penangkap kepiting bakau di Kampung Nelayan. Dengan adanya kegiatan ekowisata di kawasan hutan mangrove secara tidak langsung masyarakat juga akan ikut berpartisispasi dalam menjaga pelestarian mangrove serta diharapkan membantu meningkatkan kesejahteraan nelayan.

\section{Peluang Pendanaan CSR}

Kegiatan pengembangan Desa Binaan USU di Kampung Nelayan Sebrang memiliki tujuh topik kegiatan dan salah satunya adalah ekowisata. Kegiatan pengembangan ekowisata sendiri menurut roadmap yang disusun paling tidak memerlukan 5 tahun (2020-2024) agar bisa berjalan sesuai dengan parameter seperti yang disajikan dalam Gambar 4 .

Keberadaan Belawan sebagai pelabuhan terbesar ketiga di Indonesia, memberi peluang untuk mencari dana pengembangan ekowisata ini. Salah satunya adalah melalui mekanisme CSR (Corporate Social Responsibility) dari perusahaan yang memanfaatkan jasa Pelabuhan Belawan. Bila dana CSR dapat dikelola diharapkan dapat mendukung upaya pengelola dalam penyediaan fasilitas trekking dan sarana wisata lainnya yang memelukan biaya cukup besar.

Tahap awal dana pengabdian USU hanya mampu membuat jalur trekking sepanjang 40 meter dan 1 lokasi selfie spot. Kegiatan PKM Desa Binaan ini rencana akan diusulkan kembali ke LPPM USU dengan skema multiyears, agar capainnya sesuai target. Keberadaan USU ke depannya sangat diperlukan sebagai pendamping mitra program dalam peningkatan kapasitas pengelola ekowisata.

\section{Pembelajaran Pengembangan Ekowisata Pesisir Belawan}

Kawasan Pesisir Belawan merupakan daerah strategis di Utara Kota Medan. Selain dekat dengan pelabuhan, kawasan ini juga sangat padat penduduk. Sudah sejak lama masyarakat Pesisir Belawan memiliki ketergantungan dengan hutan mangrove. Kelestarian hutan mangrove terancam oleh aktifitas illegal baik untuk bahan baku arang maupun untuk bahan konstruksi jalan atau rumah di perkampungan. Kegiatan Desa Binaan USU dapat menjadi alternatif solusi bagi masyarakat yang rindu sentuhan inovasi bagaimana pemanfaatan mangrove secara lestari dan dilakukan secara legal.

Untuk mengembangkan ekowisata mangrove di Pesisir Belawan, LPPM USU berkoordinasi dengan Dinas Kehutanan SUMUT agar bisa bermitra dengan masyarakat Kampung Nelayan Seberang. Keberadaan LPPM USU sebagai penghubung komunikasi dan fasilitator tersebut berjalan cukup efektif. Komunikasi yang baik dan

$$
\text { Lingkungan Hidup dan Kebencanaan }
$$


didukung adanya kesepakatan antara USU dengan Pemerintah Provinsi SUMUT menghasilkan sinergitas kelembagaan yang lebih cepat.

Posisi LPPM dalam diseminasi ilmu pengetahuan menjadi lebih terasa dampaknya ketika dapat bersinergi dengan para pihak dalam membantu upaya peningkatan kesejahteraan masyarakat. Peran Dinas Kehutanan SUMUT yang sangat responsif terhadap kegiatan pengabdian ini membuat proses implementasi program tidak terlalu birokratis.

Pelajaran penting dari kegiatan pengabdian ini adalah Perguruan Tinggi dapat berperan menjembantani akses masyarakat terhadap sumberdaya alam. Hal yang selama ini menjadi gap (kesenjangan) masyarakat dalam memanfaatkan sumberdaya hutan secara lestari untuk memenuhi penghidupannya. LPPM USU berperan sebagai akselerator pemenuhan hak masyarakat sekitar hutan mangrove untuk bisa memanfaatkan seumberdaya alam tanpa merusaknya. Masyarakat yang menjadi mitra binaan juga pada akhirnya akan berperan penting dalam menjaga kelestarian hutan yang memberi manfaat secara berkelanjutan.

\section{KESIMPULAN}

Inisiasi pengembangan ekowisata di Pesisir Belawan merupakan tahap awal untuk mendukung upaya peningkatan kesejahteraan masyarakat berbasis sumberdaya lokal dengan tetap memelihara kelestarian lingkungan. LPPM USU telah berperan dalam menjembatani keinginan masyarakat Kampung Nelayan Sebrang untuk memiliki akses pengelolaan mangrove berbasis ekowisata dengan menjadi mitra resmi Dinas Kehutanan SUMUT. Selain itu masyarakat juga sedang merintis Koperasi Nelayan Cinta Mangrove yang dapat menjadi wadah penggerak perekonomian masyarakat.

Pembangunan fasilitas trekking dan pendukung lainnya masih membutuhkan biaya yang sangat besar. Potensi dan peluang yang ada sangat mendukung upaya pengembangan ekowisata di Pesisir Belawan. Semangat dari masyarakat dan kepercayaan pihak terkait menjadi kunci penting dalam mewujudkan cita-cita ekowisata Pesisir Belawan. Kegiatan ini selayaknya bisa diusulkan menjadi multi tahun karena masih ada target yang belum terlaksana. Selaini itu kegiatan ini juga sangat layak didukung oleh program CSR untuk pengimplementasiannya.

\section{UCAPAN TERIMAKASIH}

Ucapan terimakasih disampaikan kepada Kepala Dinas Kehutanan Provinsi Sumatera Utara, Dinas Koperasi Sumatera Utara, Camat Medan Belawan Lurah Belawan I dan Kepala Desa Paluh Kurau, Kecamatan Hamparan Perak, Deli Serdang yang telah membantu memfasilitasi pelaksanaan kegiatan ini. Apresiasi yang tinggi juga bagi masyarakat Kampung Nelayan Sebrang yang terlibat langsung dan sangat antusias dalam kegiatan ini. Ucapan terima kasih secara khusus kami sampaikan kepada Ketua LPPM USU yang telah mendanai kegiatan pengabdian ini melalui Skim Desa Binaan berdasarkan Surat Perjanjian Penugasan No: 251/UN5.2.3.2.1/PPM/2020, sehingga kegiatan ini dapat terlaksana dengan lancar.

\section{REFERENSI}

Fandeli C. (2000). Pengertian dan konsep dasar ekowisata. Fakultas Kehutanan. Universitas Gadjah Mada, Yogyakarta. Diakses dari https://d1wqtxts1xzle7.cloudfront.net/32377091/ko nsep_ekowisata.pdf?1385142455

Ilman, M., Dargusch, P., Dart, P., \& Onrizal. (2016). A historical analysis of the drivers of loss and degradation of Indonesia's mangroves. Land use policy, 54, 448-459. doi:10.1016/j.landusepol. 2016.03.010

Kajanus, M., Kangas J., \& Kurttila M. (2004). The use of value focused thinking and the A'WOT hybrid method in tourism management. Tourism Management, 25, 499-506. doi: 10.1016/S0261-5177(03)00120-1

Kurttila, M., Pesonen, M., Kangas, J., and Kajanus, M. (2000). Utilizing the analytic hierarchy process (AHP) in SWOT analysis-a hybrid method and its application to a forest-certification case. Forest Policy and Economics, 1, 41-52. doi: 10.1016/S1389-9341(99)00004-0

Lingkungan Hidup dan Kebencanaan 518 
Leskinen, L.A., Leskinen P., Kurttila M., Kangas J., \& Kajanus M. (2006). Adapting modern strategic decision support tools in the participatory strategy process- a case study of a forest research station. Forest Policy and Economics, 8, 267-278. doi:10.1016/j.forpol.2004.06.007

Masozera, M.K., Alavalapati J.R.R., Jacobson S.K., \& Shrestha R.K. (2006). Assessing the suitability of community-based management for the Nyungwe Forest Reserve, Rwanda. Forest Policy and Economics, 8, 206-216. doi: 10.1016/j.forpol.2004.08.001

Onrizal, Purwoko, A. \& Mansor, M. (2009). Impact of mangrove forests degradation on fisherman income and fish catch diversity in eastern coastal of North Sumatra, Indonesia. Proceedings of

the International Conference on Natural and Environmental Sciences: 70-74.

Onrizal, O., Sulistiyono, N., \& Afifuddin, Y. (2016). Keanekaragaman komunitas mangrove di sekitar kawasan wisata mangrove Kampoeng Nipah, Sumatera Utara. Abdimas Talenta: Jurnal Pengabdian Kepada Masyarakat, 1, 64-69.

Rauch, P. (2007). SWOT analyses and SWOT strategy formulation for forest owner cooperations in Austria. Eur J Forest Res, 126, 413420 .

Shrestha, R.K., Alavalapti, J.R.R., \& Kalmbacher, R.S. (2004). Exploring the potential for silvopasture adoption in South-Central Florida: an application of SWOT-AHP method. Agriculture Systems, 81, 185-199.

Situmorang, R. O. (2018). Social capital in managing mangrove area as ecotourism by Muara Baimbai Community. Indonesian Journal of Forestry Research, 5(1), 21-34.

Stronza, A, Gordillo J. (2008). Community views of ecotourism. Annals of Tourism Research. 35,448-468.

Wardhani, M. K. (2011). Kawasan konservasi mangrove: suatu potensi ekowisata. Jurnal Kelautan: Indonesian, 4(1), 60-76. 